\title{
A PRESENÇA DE DIFERENTES GÊNEROS LITERÁRIOS EM OBRAS DE
}

\author{
ALAN PAULS
}

\author{
Yur Maria Sperb ${ }^{1}$ \\ Eunice Piazza Gai ${ }^{2}$
}

Resumo: Esta pesquisa aborda aspectos das obras do escritor Alan Pauls, especialmente, no que diz respeito à questão dos gêneros literários. Para isso, apresenta-se uma interpretação das seguintes obras do escritor argentino: Wasabi, O Passado, A vida descalço, História do pranto e História do cabelo. Suas obras mantém uma escrita irreverente, por meio de uma linguagem ao mesmo tempo simples e instigante, com frases longas dando vazão a ideias que se entrelaçam e demonstram a fluidez do pensamento do escritor. Considera-se importante, neste estudo, evidenciar a mescla de gêneros como uma característica que acompanha esse autor desde o início de sua carreira e como esse hibridismo alarga as possibilidades de sentido que emergem do texto, além de buscar hipóteses das causas que levam esse autor argentino a desenvolver uma escrita tão instigante.

Palavras-chave: Alan Pauls; Gêneros literários; Romance; Ensaio; Autoficção.

\begin{abstract}
This research investigates aspects of the works of writer Alan Pauls, especially about the question of literary genres. Thereby, we present an interpretation of the following works of this argentine writer: Wasabi, The Past, The barefoot life, History of tears and History of hair. His works maintains an irreverent writing, through a language both simple and exciting, with long sentences that demonstrate the fluidity of the writer's thought. It is considered important in this study highlight the mix of genres as a feature that accompanies this author since the beginning of his career and how this increases the range of meaning that emerges from the text, and seek hypotheses of the causes that make this argentine author developing this way of writing.
\end{abstract}

\footnotetext{
${ }_{1}^{1}$ Mestranda em Letras - Leitura e Cognição - da Universidade de Santa Cruz do Sul - UNISC, bolsista PROSUP/CAPES - RS, Brasil. E-mail: yurmaria@gmail.com

2 Professora do Departamento e do Mestrado em Letras da UNISC, Coordenadora do PPGL/UNISC, Universidade de Santa Cruz do Sul - RS, Brasil. E-mail: piazza@unisc.br
} 
Key-words: Alan Pauls; Literary genres; Romance; Essay; Autofiction.

Alan Pauls é um escritor argentino, que nasceu em 1959 e teve várias obras suas traduzidas para o inglês, francês e português. Ele é, hoje, considerado um dos escritores mais originais da atual literatura latinoamericana. Além do seu trabalho como autor, lecionou teoria literária na Universidade de Buenos Aires, trabalhou como jornalista e escreveu vários roteiros cinematográficos. Esta pesquisa aborda aspectos das obras desse escritor, especialmente, no que diz respeito à questão dos gêneros literários. Para isso, apresenta-se uma interpretação de Wasabi, O Passado, $A$ vida descalço, História do pranto e História do cabelo. De modo geral, suas narrativas mantêm uma escrita irreverente, por meio de uma linguagem ao mesmo tempo simples e instigante, com frases longas dando vazão a ideias que se entrelaçam e demonstram a fluidez do pensamento do escritor. A apresentação de concepções teóricas em relação aos gêneros literários e a reflexão sobre a evolução do que se conhece sobre esse assunto foram fundamentais para um aprofundamento da interpretação das obras de Alan Pauls.

As primeiras obras de Alan Pauls são $O$ pudor do pornógrafo e $O$ colóquio - além de vários ensaios, principalmente, sobre Borges e Manuel Puig. Assim, Wasabi, publicado em 1994, é considerado o terceiro romance do autor argentino. Essa obra, porém, tratada por muitos críticos como romance, tem nítidos aspectos de novela, e inclusive do conto fantástico, mesclados com outros que poderiam ser considerados autobiográficos, por exemplo, pelo tom que a narrativa assume ao ser escrita em primeira pessoa, e por tratar de um jovem escritor que é convidado a passar uma temporada na França. Em 1992, Alan Pauls passou dois meses na Maison des Écrivains Étrangers et des Traducteurs, na França, experiência que teria dado origem a essa obra. A personagem principal de Wasabi é um homem que ingeria uma pomada homeopática, indicada para o tratamento de uma espécie de quisto que apareceu em suas costas. Ele, ao invés de fazer o uso tópico desse medicamento, usava-o como alucinógeno por via oral, à medida que a sua enfermidade ia se tornando uma verdadeira anomalia. Assim, existe espécie de 
investigação acerca de temas relacionados ao corpo no decorrer da narrativa. O próprio autor, em entrevistas concedidas sobre essa obra, afirma que o que escreve poderia se chamar de "ficção doente", entendendo a doença como princípio de mutação que afeta tudo, corpo, alma, capacidade de narrar, relação com o mundo. Segundo ele, "a doença aparecia como um quisto que crescia desmesuradamente nas costas do narrador e nas tentativas que este fazia para curar-se".

Ao se buscar uma definição de romance, consideram-se as ideias de Yves Stalloni, autor francês, que agrupa os romances em oito categorias, dividindo-os de acordo com os seguintes critérios: o contexto da intriga, se pastoral, regionalista, exótico; a ação, se de aventura, policial, de espionagem; e a técnica narrativa, se autobiográfico, epistolar, ou um romance em primeira pessoa. De acordo com esses critérios, as oito categorias do romance seriam: heroico, cômico, picaresco, por cartas, de formação (ou de educação), histórico, autobiográfico e o Nouveau Roman:

A repartição em subcategorias é uma comodidade metodológica que permite a identificação de uma obra [...]. Mas essa abordagem não é de grande valia para o estabelecimento de uma definição estável de romance (STALLONI, 2007, p. 108).

Por outro lado, ao se tentar precisar uma definição de novela, o que se tem é a certeza de que ela constitui uma narrativa mais breve do que o romance, abrangendo menos personagens, que só apresentam de fato sua evolução psicológica na medida em que se envolvem no acontecimento que é central para a narrativa. Ainda que alguma confusão ou imprecisão reste desse conceito, há de se considerar o seu aspecto narrativo e o seu formato, que é geralmente breve. A brevidade apresentada por esse gênero constitui, então, sua oposição mais definida em relação ao romance, "ainda que esses limites de extensão tenham podido variar no tempo e no espaço e que os próprios interessados tenham mostrado a aproximação entre as etiquetas" (STALLONI, 2007, p. 113). Dessa forma, a densidade se impõe como traço incontestável para o reconhecimento da estética da novela. 
Ainda assim, pode-se identificar três particularidades próprias desse gênero: a unidade da ação, que corresponde a considerar que a novela se organiza em torno de um acontecimento único, podendo seu argumento, frequentemente, ser resumido em uma única frase; a narração monódica, que faz com a história seja contada por meio de um único narrador, que a conduz do início ao fim; a ambição da verdade, apresentando uma visão do mundo como fiel. "Essa verdade é percebida tanto no valor de testemunho quanto na revelação psicológica que permite à personagem, projetada na nudez de sua experiência, ir ao encontro de uma verdade subjetiva" (STALLONI, 2007, p. 117-118). Dessa forma, pode-se considerar que esses critérios de identificação da novela, apesar de reais, são também imprecisos, como já se chegou à conclusão no romance.

Para organizar o estudo do conto, Stalloni (2007) propõe que se destaquem os seguintes traços distintivos:

- o conto inclina-se em direção à fabula ou ao onirismo, renunciando ao realismo e à verossimilhança;

- suas personagens pertencem ao domínio do simbólico, abandonando as caracterizações individuais;

- ele possui um fundamento popular, podendo inspirar-se na tradição oral e coletiva ou no folclore;

- ele pode ser (pelo menos teoricamente) mais longo do que a novela, mas é, como esta, um relato breve;

- ele procede de uma narração direta, inspirada pela oralidade: um narrador que se assume como tal "recita" a história;

- ele comporta uma intenção moral ou didática, claramente expressa, ou implicitamente contida na narrativa (2007, p. $120-$ 121).

Assim, percebe-se que algumas dessas características aplicam-se exclusivamente ao conto, enquanto outras são aplicáveis também à novela. Dessa forma, se tem a distinção dos contos em quatro categorias: o conto gaulês, o conto maravilhoso, o conto filosófico e o conto fantástico. O conto fantástico, que muito se aproxima do conto maravilhoso, chegando a ser considerada qualquer distinção entre eles como artificial, "mas a crítica moderna soube mostrar as diferenças e até mesmo sublinhar suas oposições em relação a este" (STALLONI, 2007, p. 124). O fantástico tem, por exemplo, como impulso fundamental da narração o medo, pelo aparecimento inexplicável 
do sobrenatural, que surge em um universo realista e verossímil. Ao considerar as concepções apresentadas por Stalloni, fica nítida a mescla que se pode perceber em Wasabi de diferentes aspectos do romance, da novela e até do conto. O parágrafo seguinte encerra essa obra de Alan Pauls:

Só eu teria podido enumerar esse inventário secreto; eu, que tinha sido desterrado para sempre da nublada luminosidade daquela tarde em Saint-Nazaire, eu, que contemplava a esse homem jovem, sentado no chão, com um livro esquecido entre as coxas, com que se compara o retrato de um morto. A mulher gritou, seu uivo de besta reduziu a pó todos os sons do mundo. Soube então quão mais estranha é a juventude que a ficção, e que o filho que velava insone dentro de sua mãe adormecida havia encontrado finalmente a seu pai (PAULS, 1996, p.127).

Já em $O$ Passado, em uma narrativa de quase quinhentas páginas, divididas em quatro partes, que são por sua vez divididas em capítulos curtos na sua grande maioria, Alan Pauls apresenta um protagonista também acometido por uma estranha doença: um tradutor que vai perdendo, aos poucos, todas as línguas que conhece. Nas entrevistas concedidas pelo autor, ele próprio chama essa anomalia de "meu pequeno Alzheimer linguístico", afirmando que: "o que me interessa desses processos patológicos é que são integrais e que produzem novas formas de vida". Narrado em terceira pessoa, essa longa narrativa, catalogada como ficção argentina, também contempla características próprias do romance, da novela, e do conto, especialmente quanto ao contexto da intriga, à ação e à técnica narrativa. Assim, uma definição mais precisa passará pelo exame de cada uma das realizações literárias.

História do pranto, obra lançada no Brasil em 2008, e História do cabelo, em 2011, fazem parte de uma trilogia pretendida pelo autor para representar a problemática pela qual passou a sociedade argentina na década de 70 , conhecida como "Os anos de chumbo". Ambas são narradas em terceira pessoa, em que o autor flutua entre os temas políticos e psicológicos, fazendo delas romances nada tradicionais, apresentando narrativas em que também se pode encontrar características de outros gêneros literários. Essa trilogia tornouse completa, aqui no Brasil, em meados de 2014, com o lançamento do livro História do dinheiro, que não fará parte desta pesquisa neste momento. 
Em História do pranto, o autor mescla de modo original o romance psicológico e a novela política. Ele usa o testemunho de um garoto que acreditava ser o Super-Homem para recuperar a história da esquerda argentina dos anos 1970. Jovem sensível, filho de pais divorciados de classe-média em Buenos Aires, o protagonista se depara com uma encruzilhada entre sua sensibilidade e a formação política. Segue, então, em busca de uma revisão ideológico-sentimental de sua vida, numa trajetória que reúne um repugnante cantor de protesto, uma namorada chilena de direita, um oligarca torturado, um vizinho militar que talvez não seja o que parece, e um inusitado polvo no fundo de uma piscina. Em uma narrativa surpreendente, que une longos parágrafos e frases de ritmo rápido, o romance traz uma rara integração entre descrição e digressão, marca registrada de Alan Pauls:

A dor é o excepcional e, por isso, o que não se pode suportar. Divide os episódios em duas categorias incomparáveis, aqueles em que intervêm e aqueles em que não intervêm as pedras fatais. Despreza os segundos, confinando-os à última gaveta de seu armário, a mesma na qual vão juntando pó as revistas, os brinquedos e os livros que a sua maturidade vai deixando para trás, que agora detesta e que mais tarde, ao sentir-se fora de sua órbita de influência, exuma com fervor e adora, testemunhos do idiota inocente que ele já não é, mas com o qual agora não pode senão se enternecer (PAULS, 2008, p. 8).

Para concluir o estudo desse capítulo sobre o romance e o gênero narrativo, Stalloni (2007) esclarece que

seria possível acrescentar a essa enumeração procduções literárias que utilizam 0 modo narrativo de outras formas diversamente representadas em literatura: o relato de viagem, a crônica histórica, a parábola, a história engraçada, as memórias... Essas diferentes expressões escapam muitas vezes ao estrito domínio literário, ou não passam de casos particulares no interior de "espécies" mais amplas, já descritas (p. 127).

O segundo volume da trilogia, História do cabelo, narra a aventura de um homem obcecado por cabelo. Uma personagem que vaga por Buenos Aires entrando e saindo de salões, condenado a pensar no cabelo: se deve cortar 
muito, pouco, deixar crescer, não cortar mais, raspar a cabeça para sempre. Em busca do corte perfeito, e em meio a uma infinidade de reflexões sobre o cabelo (cortes de cabelo, cabelereiros, salões, xampus, produtos de cabelo, estilos, o cabelo como o símbolo social, instrumento político e de identidade), o protagonista se vê envolvido numa trama que remonta a um dos períodos mais sombrios da vida social e política argentina. E é justamente através do cabelo que a história, que se inicia como a saga muito pessoal de um fetiche, se cruza com a luta armada. A preocupação com o cabelo, que parece tão insipiente diante da situação pela qual a Argentina passa naquele momento, revela esse herói que não se enquadra nos moldes tradicionais. Ele é, sim, esse novo herói contemporâneo, que é pleno de incertezas, e não mais o ser invencível.

Ao romance histórico que está previsto pelo caráter das obras dessa trilogia, soma-se o tom psicológico apresentado pelo protagonista:

\begin{abstract}
Uma vez, no verão, fugindo do calor - são quatro da tarde, quase não tem gente na rua-, entra num salão deserto. Lavam sua cabeça. Está reclinado, com a nuca apoiada na canaleta de plástico. Mesmo com desconforto e dor no pescoço, [...] a massagem dos dedos, a doce nuvem de perfume vegetal que se desprende de sua cabeça e a pressão dos jatos de água morna o inebriam, transportando-o pouco a pouco a uma espécie de devaneio. Não demora a dormir. Ao abrir os olhos novamente, a primeira coisa que vê, fora de foco de tão perto, como se estivesse pintado sobre uma superfície de areias movediças, é o rosto da garota que lava o sua cabeça. [...] Ainda acordando, não consegue se lembrar, embora tente, como era mesmo aquele rosto dez minutos atrás, quando tinha acabado de entrar no salão [...] (PAULS, 2011, p. 7-8).
\end{abstract}

Esse tom, ao mesmo tempo descritivo e psicológico, além da mescla de vários gêneros literários considerados pelos cânones clássicos, se confirma de forma especialmente evidente em A vida descalço. Lançado no Brasil em 2013, esse livro surgiu através de um projeto da editora Sudamericana, de Buenos Aires, que decidiu lançar uma coleção sobre lugares. Ao aceitar o desafio de escrever sobre a praia, cenário comum para o cinema e raro em obras literárias, Alan Pauls, em entrevista a Suzana Velasco, declarou ter sido tomado por lembranças, impressões e experiências surpreendentes para ele mesmo. Ainda assim, o autor também afirma que fez questão de, além de falar 
de si próprio, em certos momentos tomar distância dos fatos para se tornar uma espécie de narrador cultural.

A obra $A$ vida descalço foi sempre considerada um ensaio literário por, de fato, apresentar várias características próprias desse gênero. O próprio Alan Pauls, em entrevista a Hugo Viana, defende a escolha desse gênero por ser o ideal para transformar temas aparentemente banais, como a praia, em uma verdadeira teia de assuntos complexos. A vida descalço apresenta uma série de textos curtos sobre experiências vividas na praia. Com um tom autobiográfico, essa obra foi, desde o seu lançamento, classificada como uma coletânea de ensaios, baseados nas lembranças da infância e da adolescência de um homem durante os verões no litoral, revelando leituras marcantes para a personagem, como Todos os fogos o fogo, de Júlio Cortázar, além de fatos corriqueiros nesse cenário, como perder-se dos pais na areia.

A obra é catalogada como ensaística, porém outros traços também são percebidos, inclusive os de um romance. Há aspectos de autobiografia, autoficção, sem abandonar totalmente a ficcionalidade, o ensaio e o romance. Essa mescla de gêneros torna imprescindível apurar a interpretação e, nesse sentido, o entendimento sobre o percurso do estudo dos gêneros literários tem relevante papel. Essa postura investigativa diante das concepções de gêneros ajuda de forma decisiva a escutar melhor os textos, numa atitude, que é a que se pretende neste trabalho, hermenêutica. Além disso, pode-se considerar que, ao mobilizar o imaginário para narrar e constituir todos os aspectos que isso envolve, pode-se afirmar que a identidade que se cria é o imaginário. Nesse sentido, consideram-se as ideias do francês Philippe Lejeune, "a autobiografia que corresponde a esse imaginário está do lado da verdade. Nenhuma relação com o jogo deliberado da ficção" (p. 104).

Outra questão abordada por Lejeune, relacionando as narrativas ficcionais às autobiografias, diz respeito ao fato de, muitas vezes, haver uma tentativa de negar esse caráter autobiográfico, como se ele diminuísse a posição de seus criadores. Felizmente, apesar de o preconceito existir, a escrita autobiográfica não só se mantém como cresce em relação ao número de obras publicadas desse tipo: "há, na França, tanta hostilidade e irritação em torno da autobiografia "autêntica" que um certo número de escritores 
acampam, se posso dizer assim, 'ilegalmente' em seu território" (LEJEUNE, 2008, p. 108). Esses autores franceses, a que Lejeune se refere, transitam entre as duas zonas, o que torna a obra mais viva, mestiça, rica em criação. $O$ que se tem é um misto, uma mescla de verdade e ficção, de contrato e invenção, enriquecendo o gênero autobiográfico como um traço entre outros que as obras podem apresentar.

O escritor francês Serge Doubrowsky, ao conhecer as ideias de Lejeune e seu pacto autobiográfico, motivou-se a escrever Fils, narrativa em primeira pessoa, em que o narrador-personagem tem o seu próprio nome. Apesar disso, os fatos narrados são puramente ficcionais. Para Lejeune, mesmo nome para autor e personagem seria evidente caráter de autobiografia, porém, essa obra, por jogar com os limites entre verdade e ficção, deu origem ao conceito de autoficção. Assim, a autoficção estaria entre o romance e a autobiografia, narrativa em que o leitor não sabe, afinal, se o registro é verdadeiro ou falso, confundindo-o acerca do que o autor diz ou pensa. $O$ termo, que foi usado pela primeira vez por Doubrowsky, em 1977, caracteriza o conjunto de obras literárias que apresentam passagens da vida ou, até mesmo, características físicas e psicológicas do autor em um contexto claramente ficcional. Então, a caracterização dos gêneros literários, com traços ou normativos ou descritivos, apresentando ou regras inflexíveis ou apenas um conjunto de aspectos semelhantes, os quais as obras devem apresentar em sua totalidade ou predominantemente, vem se diferenciando a cada época. Muitos teóricos chegaram a ver os gêneros literários como categorias imutáveis, valorizando as obras de acordo com a fidelidade que o autor imprime a essas leis.

Outros, porém, ressaltam a necessidade da liberdade criadora que deve resultar do trabalho artístico, defendendo, dessa forma, a possibilidade da mistura de diferentes gêneros. E, a partir da conclusão de Yves Stalloni (2007) de que "reconhecer o gênero de uma obra é, inevitavelmente, recolocá-la a um só tempo na perspectiva da história literária e na da crítica analítica" (p. 184), tem-se a certeza da importância dessa revisão das concepções de gêneros literários para se seguir adiante com a leitura, interpretação, escuta, estudo de obras literárias. Essa mescla é uma alternativa a mais para a configuração do estilo do autor. Assim, o hibridismo não é apenas mais um gênero que se somará aos outros, é sim uma questão de estética. Considera-se importante, |78| Revista Eletrônica Literatura e Autoritarismo, no 24 - julho a dezembro de 2014 - ISSN 1679-849X http://cascavel.ufsm.br/revistas/ojs-2.2.2/index.php/LA/index 
neste estudo, evidenciar a mescla de gêneros como uma característica que acompanha Alan Pauls desde o início de sua carreira e como esse hibridismo alarga as possibilidades de sentido que emergem dos seus textos. Com isso, torna-se necessária uma escuta mais apurada de suas narrativas pela diversidade de sentidos que estão emergindo da leitura de um texto que apresenta surpresas com a riqueza de mesclar diversos gêneros e que parece, por meio desse hibridismo, estar sempre criando um gênero novo. Talvez não se trate de um novo gênero e sim de uma nova estética ou de uma constante possibilidade de o autor reinventar seu estilo.

\section{REFERÊNCIAS}

ARISTÓTELES. Poética. In: et alii. A poética clássica. São Paulo: Cultrix, 1985.

COLOMBO, Sylvia. Escritor portenho Alan Pauls tem novo romance lançado na Argentina. Folha Online, jan. 2004. Disponível em:

http://www1.folha.uol.com.br/folha/ilustrada/ult90u41032.shtml. Acesso em: 19 dez. 2014.

CUNHA, Helena Parente. Os gêneros literários. In: PORTELLA, Eduardo et.al. Teoria literária. Rio de Janeiro: Tempo Brasileiro, 1973.

DOUBROVSKY, Serge. Autobiographiques. Paris: PUF, 1988. . Fils. Paris: Galilée, 1977.

HORÁCIO. In: et alii. A poética clássica. São Paulo: Cultrix, 1985.

LEJEUNE, Philippe. O pacto autobiográfico: de Rousseau à Internet. Trad. De Jovita Maria Gerheim Noronha e Maria Inês Coimbra Guedes. Belo Horizonte: Ed. UFMG, 2008.

LIMA, Luiz Costa. A questão dos gêneros. In: . Teoria da literatura em suas fontes. Rio de Janeiro: F. Alves, 1983.

MONTAIGNE, Michel de. Ensaios. 3. ed São Paulo: Abril Cultural, 1984.

PAULS, Alan. A vida descalço. São Paulo: Cosac Naify, 2013. 
. História do cabelo. São Paulo: Cosac \& Naify, 2011.

. História do pranto. São Paulo: Cosac \& Naify, 2008.

. O passado. São Paulo: Cosac \& Naify, 2007.

Wasabi. São Pulo: lluminuras, 1996.

PEREIRA, Maria Helena R. Prefácio. In: ARISTÓTELES. Poética. Lisboa: Fundação Calouste Gulbekian, 2004.

PLATÃo. A República. São Paulo: Escala - Coleção Grandes Obras do Pensamento Universal.

SILVA, Vítor Manuel de Aguiar e. Teoria da literatura. 3 ed. Coimbra: Almedina, 1973.

SOARES, Angélica. Gêneros literários. São Paulo: Ática, 2007.

STAIGER, Emil. Conceitos fundamentais da poética. Rio de Janeiro: Tempo Brasileiro, 1997.

STALLONI, Yves. Os gêneros literários. São Paulo: Difel, 2001.

VELASCO, Suzana. Geografia em branco. Disponível em: $<$ http://editora.cosacnaify.com.br/Upload/Saiulmprensa> Acesso em: 30 jun. 2013.

VIANA, Hugo. Literatura, praia e pés descalços. Disponível em: <http://www.folhape.com.br> Acesso em: Acesso em: 30 jun. 2013. 